development. "The survey provides evidence of an intelligent, professionally committed group of members," commented Susan Stussy, director of libraries at St. Norbert College and a member of ACRL's Membership Committee, which directed staff to work on the quintennial survey.

Betsy Hine, monograph cataloger at Indiana State University, who also serves on the Membership Committee, noted "It seems to me that what
ACRL does now ranks quite high ... the membership seems fairly happy with what ACRL is doing... Response(s) reflect a very pragmatically oriented group."

As ACRL carries on its regular planning process, and as individual committees plan activities over the next years, this survey will provide a helpful guide to members' opinions.

\title{
Curriculum materials in online
}

\section{catalogs}

\author{
Developed by the \\ EBSS Curriculum Materials in the Online Catalog ad hoc Subcommittee*
}

Rolland H. McGiverin, Chair

\section{Standardized cataloging for curriculum centers.}

his paper is to assist curriculum librarians, systems personnel, and catalogers who have responsibility for preparing curriculum materials for inclusion in online catalogs in academic libraries. Curriculum materials in this document are defined as materials traditionally found in curriculum centers, e.g., curriculum guides, elementary and secondary textbooks, instructional media, and juvenile literature. This document will give an overview of the history of cataloging curriculum materials and identify cataloging issues which are unique to curriculum materials to facilitate the inclusion of these materials in online catalogs.

\section{Historical background}

In the early decades of this century, curriculum laboratories or centers were developed at various colleges of education to study, improve, revise, and produce elementary and secondary school curricula. As their products and programs became im-

${ }^{\circ}$ Editor's Note: This is a joint subcommittee of the EBSS Problems of Access and Control of Education Materials Committee and the EBSS Curriculum Materials Committee. Its members are as follows: Rolland H. McGiverin (chair), Indiana State University; Joan Berman, Humboldt State University; Doris Brookshier, Central Missouri State University; Lawrence Marble, Temple University; Virginia Nordstrom, Queens College; and Ilene Rockman (chair of the EBSS Problems of Access and Curriculum Materials Committees), California Polytechnic State University. The authors extended their appreciation to Allison Kaplan, University of Delaware, and Kathleen McGowan, University of Rochester, for their assistance in the preparation of this document. 
portant components in teacher training programs, the role of these laboratories and centers evolved to include the acquisition, organization, and management of teaching materials. Nevertheless, the origin of these centers provides some perspective on the individuality, idiosyncratic organizational style and procedural diversification of many curriculum centers. By the late 1960s, institutional responsibility for these curriculum centers had often moved from the colleges, schools, and departments of education to the academic library. With this shift in sponsorship, service emphases veered away from the creation and development of curricula to the issues of collection development; the functions of acquisitions, cataloging, management, and circulation; and instruction in collection use. ${ }^{1}$

However, even in this setting, the technologically efficient methods of contemporary academic libraries usually bypassed curriculum collections. Like many specialized materials, curriculum materials have not received an equal measure of attention in the development of national cataloging and classification standards. Various factors may account for this: 1) the physical separation of the center from the main library; 2) the omission of the center's purpose from the mission statement of the library; 3) differences in orientation and philosophy between the center and the library; 4) the center's lack of access to bibliographic tools and equipment; 5) the perception that the materials are ephemeral; 6) the library's lack of understanding of the special nature of curriculum materials; 7) confusion over the definition of curriculum materials; and 8) the low priority given to cataloging "special materials" due to the lack of cataloging staff. The absence of national standards for the cataloging of curriculum materials ${ }^{2}$ has fostered the development of numerous local systems which has further isolated curriculum materials from the main flow of bibliographic access in the academic library.

\section{Online catalogs and bibliographic utilities}

As a result of the introduction of online public access catalogs (OPACs), cataloging practices for

${ }^{1}$ For an excellent review of the history of curriculum materials centers, see Alice S. Clark, Managing Curriculum Materials in the Academic Library (Metuchen, N.J.: Scarecrow Press, 1982).

${ }^{2}$ The cataloging standards issue has been raised by the RTSD/CCS Cataloging of Children's Materials Committee, "Guidelines for Standardized Cataloging of Children's Materials," Top of the News, Fall 1983, pp. 49-55. For this committee's most recent efforts, see Cataloging Correctly for Kids: An Introduction to the Tools (Chicago: American Library Association, 1989). curriculum materials have emerged as a particularly salient area of concern for the curriculum librarian. The failure to include these materials in OPACs leads to user frustration, underutilization of materials, and the perpetuation of labor intensive and expensive practices for the selection, cataloging, and circulation of curriculum materials. ${ }^{3}$ However, the lack of standardized methods for the cataloging and classification of curriculum materials often results in the exclusion of these materials from OPACs. A recent study analyzing representation of these materials in the OCLC database concludes that there has been an appreciable increase in the last decade in the availability of usable records for curriculum materials. ${ }^{4}$

\section{The MARC record}

The following MARC fields are important to consider when preparing for the inclusion of curriculum materials in OPACs or bibliographic utilities. If the cataloging is completed outside of the curriculum center, early consultation with the curriculum librarian will be necessary.

\section{0, 082, 090, 092, 099 (call number fields)}

Although both the Dewey (DDC) and Library of Congress (LC) classification systems have been used for classifying curriculum materials, the lack of guidance for cataloging curriculum materials has encouraged many centers to either modify DDC or LC or to create their own classification systems. Some centers even use different schemes for different types of materials. Nevertheless, such unique classification systems can be accommodated by using the 099 field. It should be noted that Dewey call numbers are incomplete in the 082/092 fields of the MARC record and must be completed by the library using the record. If the 099 field is routinely used for curriculum materials, attention must be given to the sequence of the call number fields selected for processing tapes for an online catalog.

\section{lxx (main entry) and 245 (title)}

There are no unusual problems in these fields regarding description. Curriculum librarians generally prefer to catalog textbook sets as sets rather

${ }^{3}$ Carole F. Wilson, Mary M. Finley, and Alice S. Clark, "Cataloging Practices and Resource Sharing of Curriculum Collections in Academic Libraries," Journal of Library Administration 6 (Winter 1985/ 86): 81-88.

${ }^{4}$ Jack Kranz, "Cataloging of Curriculum Materials on OCLC: A Perspective," Cataloging \& Classification Quarterly 8, no.2 (1988): 15-28. 
than as individual titles. Care should be taken to differentiate sets from series.

\section{0 (edit on statement)}

Textbook sets typically include both student and teacher editions of the main text and workbooks. Some centers acquire the complete set, whereas other centers may acquire only the teacher edition. There is a philosophical question as to whether a teacher edition constitutes a true edition statement or is a vital part of a set. Local practice will dictate whether the teacher edition is noted here or in the 300 field.

\section{0 (collation)}

This field is where all the various parts of a set will be recorded, usually using subfield " $\mathrm{e}$ ".

\section{$4 \mathrm{xx} / 8 \mathrm{xx}$ (series information)}

Series is an essential access point for curriculum materials and must be traced.

\section{Attention, authors!}

College \& Research Libraries News welcomes manuscripts submitted on diskette or via ALANET. The C $d R L$ News ALANET number is ALA0306. If you can upload it, I can download it, because ALANET translates text into pure ASCII files. If you don't have ALANET or you prefer to send a diskette, make sure it is formatted for MS-DOS; either 5.25-inch or 3.5-inch diskettes can be accepted.

We use Xywrite III + for word processing, but we translate files from other major programs. When submitting a diskette with a file created by another word processing program, it is best to also include an ASCII text file.

Always send a paper copy of your manuscript along with the diskette, just in case we cannot read your file.

If you can neither send a diskette nor transmit via ALANET, submit three paper copies in a standard typeface such as Courier or Pica. Please avoid sending proportional or oversize typefaces. Do not fax articles unless you are requested to.

Queries are not required. If you need clarification on the appropriateness of your topic, please call rather than write.

Submit all materials to George M. Eberhart, Editor, C\&RL News, ACRL/ALA, 50 E. Huron St., Chicago, IL 60611; (312) 280-2511.GME.

\section{$5 x x$ (notes fields)}

Notes give useful descriptive information that cannot be accommodated in the rest of the bibliographic description. Multiple as well as lengthy notes are ordinarily used for curriculum materials and care must be given in deciding which fields will be used routinely. Typical notes include plot summary (especially for children's literature), titles of parts of sets (contents note), intended audience (grade level), reading level, and state adoption. The online catalog selected must be able to accept not only multiple notes but lengthy ones as well. $\mathrm{Al}$ though the order of notes is prescribed by AACR2, order of display of notes fields in an online system is of particular concern for curriculum centers. If the contents note cannot be indexed in the online catalog then the titles of parts of sets should be given title added entries (7xx).

\section{6xx (subject added entries)}

Frequently the curriculum materials collection is governed by a different subject authority than the library's main collection, e.g., the curriculum collection may use Sears, Library of Congress Children's Subject Headings, or nonstandard headings while the main collection uses Library of Congress Subject Headings (LCSH). Of major concern in implementing an online system will be how the vendor of choice accepts and maintains multiple subject heading authorities and whether patron searching can be limited by collection. This will inevitably be an area where careful decisions will need to be made.

\section{7xx (author and title added entries)}

Access by publisher and corporate author is essential for patrons of curriculum collections. It is also important to provide access to the titles of parts of sets listed in a 5xx contents note.

\section{Recommendations}

1. Curriculum materials should be accessible in OPACs either in a separate catalog or as part of a union catalog.

2. Bibliographic records should be placed on a bibliographic utility. When appropriate, the main entry should be for the set, and should contain information for the parts of that set, the grade and reading levels, and the DDC or LC call number.

3. Curriculum librarians should consider the adoption of standardized classification and subject heading systems.

4. Curriculum librarians should be actively involved in issues and decisions relating to the preparation and inclusion of curriculum materials in OPACs. 


\section{Conclusion}

The growth of OPACs highlights the need for standardized curriculum cataloging procedures. The cost effectiveness of placing curriculum materials in OPACs is closely associated with the availability and quality of records in the bibliographic utilities. The rising rate of member-input records in OCLC indicates the increasing commitment of curriculum centers to shared cataloging and rein- forces the need for standardizing curriculum cataloging procedures.

The ease of transferring records from bibliographic utilities to OPACs provides further motivation for the establishment of such standardization. Cooperative sharing of bibliographic records through national utilities provides the opportunity to enhance access to curriculum materials collections.

\section{Special collections in the Southeast}

\author{
By James B. Lloyd \\ Special Collections Librarian \\ University of Tennessee, Knoxville
}

\author{
and William B. Eigelsbach \\ Senior Library Assistant \\ University of Tennessee, Knoxville
}

\section{A special report on special collections.}

\section{$\mathbf{T}$}

his survey of mid-sized academic libraries in the southeast came about in response to a specific administrative need-the perhaps universal desire for more staff. One way to prove our need was to prove that we had fewer people performing the same functions than other repositories of comparable size. Since it did not seem appropriate to ask colleagues to fill out another survey to meet such an immediate and personal need, we surveyed by phone. And we limited ourselves to mid-sized academic libraries in the southeast, since that is our environment, purposely omitting places like the University of Virginia because they are so much larger, and going no farther west than Arkansas.

As might be expected, we had some difficulty in interpreting our statistics, and sometimes were forced to call back for clarification. There seem to have been several reasons for this. For one thing the faculty, paraprofessional, clerical staffing structure which we use here does not exactly match classifications used elsewhere. For another, the figures themselves may be deceiving. Staff may be dedicated to non-visible functions, i.e., functions which we did not survey, such as microfilming or staffing an isolated public service point. The size of a repository sometimes proved difficult to compare, since conversion formulas between items and feet differed so widely that we were forced to make some adjustments on our own. And sometimes even the volume count for rare books may be unreliable. In our case, we have a second collection of some 100,000 volumes which, though not rare books is part of Special Collections. If we had chosen to count these volumes, we would have appeared much larger than we really are. 